\title{
TELESSAÚDE BRASIL REDES - NÚCLEO RIO DE JANEIRO: A EDUCAÇÃO PERMANENTE NO TRABALHO DE ENFERMEIROS DA ATENÇÃO BÁSICA
}

\author{
Brazilian Telehealth Networks Program - Rio de Janeiro Nucleus: the continuing education \\ on primary care for nurses
}

Magda Guimarães de Araujo Faria ${ }^{1}$; Helena Maria Scherlowski Leal David ${ }^{2}$

\begin{abstract}
Resumo Este trabalho objetivou identificar o perfil de enfermeiros que usam o Telessaúde como estratégia de educação permanente, analisando também o uso das ferramentas de teleconsultoria e teleconferências por estes profissionais. Nos meses estudados, a utilização dos recursos aumentou o que sugere uma busca da autogestão do aprendizado pelos atores da pesquisa através da educação a distância.
\end{abstract}

Palavras-chave: Educação a distância, Tele-enfermagem, Telessaúde

\begin{abstract}
This study aimed to identify the profile of nurses who use Telehealth as a strategy for continuing education, also analyzing the use of tools of teleconferencing and teleconsulting by these professionals. In the months studied, the tool usage increased gradually, indicating that distance education is an effective method to conduct educational activities.
\end{abstract}

Keywords: Distance education, Telenursing, Telehealth

O processo de educação em saúde é um dos determinantes para a qualidade da atuação das equipes de atenção básica. A educação permanente, em especial, possibilita o aprendizado dinâmico a partir das demandas do cotidiano do trabalhador. Atualmente, a educação a distância é um dos meios pelos quais os profissionais podem se aprimorar, rompendo com incompatibilidades temporais e geográficas. Com este objetivo, foi instituído em 2007, pelo Ministério da Saúde, o Programa Telessaúde Brasil, que tinha por objetivo a educação permanente a distância dos profissionais da estratégia de saúde da família, sendo o Rio de Janeiro um dos núcleos do projeto piloto. O Projeto possui duas atividades básicas: a teleconferência, funcionando de modo síncrono, em que o profissional tem a oportunidade de participar de aulas sobre temas de interesse com possibilidade de interação; e, a teleconsultoria que, de modo assíncrono possibilita ao trabalhador obter a opinião de um especialista sobre qualquer dúvida de seu cotidiano. Esta pesquisa, analisando a população de enfermeiros no estado do Rio de Janeiro, teve como objetivos: (a) Identificar e caracterizar, do ponto de vista sóciodemográfico, quanto ao uso de tecnologias de Internet;

1. Professora substituta do Departamento de Saúde Pública da Faculdade de Enfermagem. Mestre em Enfermagem. Doutoranda do Programa de Pós-graduação da Faculdade de Enfermagem. Universidade do Estado do Rio de Janeiro. - Mestre em Enfermagem. 2. Professora Adjunta do Departamento de Saúde Pública da Faculdade de Enfermagem. Doutora em Saúde Pública. Diretora da Faculdade de Enfermagem. Universidade do Estado do Rio de Janeiro. - Doutora em Saúde Pública. Endereço Eletrônico: mag_araujo@yahoo.com.br (Magda Guimarães de Araujo Faria). 
(b) Identificar, categorizar e analisar as principais demandas de educação permanente; (c) Descrever e analisar a participação dos enfermeiros em atividades específicas. A metodologia utilizada foi quantitativa, com desenho longitudinal e observacional, delineamento de pesquisa não experimental e caráter descritivo. Os dados foram obtidos entre os anos de 2009 e 2010 utilizando três fontes: formulários de linha de base, registro de teleconferências e registros de perguntas e respostas de segunda opinião formativa. Os resultados indicam certa homogeneidade no perfil do profissional enfermeiro atuante em território fluminense. Este é composto por trabalhadores em sua maioria do sexo feminino, jovens de formação recente, especialistas e com conhecimentos básicos sobre tecnologias de informação e comunicação. Quando se fala de uso das tecnologias de internet, observa-se que o profissional residente na região metropolitana utiliza com maior frequência a rede mundial de computadores para fins educativos. Verificou-se que a maior parte das dúvidas do enfermeiro da ESF ainda é pautada em dúvidas clínicas, seguidos de dúvidas sobre implementação de atividades em educação permanente. Conclui-se que a educação a distância é uma estratégia viável para desenvolver atividades de educação permanente. Entretanto, alguns desafios ainda devem ser superados, como as dificuldades técnicas e a ausência de habilidade para manusear os recursos de informática. 